\title{
Familial hypofibrinogenemia
}

INSERM

\section{Source}

INSERM. (1999). Orphanet: an online rare disease and orphan drug data base. Familial hypofibrinogenemia. ORPHA:101041

Familial hypofibrinog enemia is a coagulation disorder characterized by mild bleeding symptoms following trauma or surgery due to a reduced plasma fibrinogen concentration. 